Article

\title{
Parental Non-Engagement within Child Protection Services-How Can Understandings of Complex Trauma and Epistemic Trust Help?
}

\author{
Claire Mason ${ }^{1, *}$, Danny Taggart ${ }^{2}$ and Karen Broadhurst ${ }^{1}$ \\ 1 Centre for Child and Family Justice Research, Department of Sociology, Lancaster University, \\ Lancaster LA1 4YD, UK; k.broadhurst@lancaster.ac.uk \\ 2 School of Health and Social Care, University of Essex, Colchester CO43SQ, UK; dtaggart@essex.ac.uk \\ * Correspondence: c.mason@lancaster.ac.uk
}

Received: 14 October 2020; Accepted: 16 November 2020; Published: 26 November 2020

\begin{abstract}
Building on the findings from the national study of mothers in recurrent care proceedings in England, this paper proposes that the concepts of complex trauma and epistemic trust may help explain parents' difficulties in engaging with child protection services. With the aim of advancing theoretical knowledge, qualitative data drawn from interviews with 72 women who have experienced repeat care proceedings are revisited, with a focus on women's developmental histories and accounts of engagement with professionals, to probe the issue of service engagement. The article starts with a succinct review of the literature on parental non-engagement in child protection, highlighting strengths and potential limitations of current knowledge. This is followed by an introduction to the theoretical concepts of complex trauma and epistemic trust, outlining how these concepts provide an alternative framing of the reasons why parents may resist, or are reluctant to engage with, professionals. Drawing on women's first-person accounts, we argue that high levels of maltreatment and adversity in women's own childhoods shape adult relationships, particularly in relation to vulnerability to harm in adult lives but also mistrust of professional help. Extracts from women's first-person accounts, chosen for their typicality against the core themes derived from the data, indicate that acts of resistance or rejection of professional help can be seen as adaptive-given women's childhoods and relationship histories. The authors conclude that parents' social histories need to be afforded far closer attention in child protection practice, if preventative services are to reach those with histories of developmental trauma.
\end{abstract}

Keywords: complex trauma; child protection; parental non-engagement; recurrent care proceedings; epistemic trust

\section{Introduction}

In 2017, the findings from a national study of mothers in recurrent care proceedings in England was published [1]. This mixed methods study provided the first estimate of the scale of women's involvement in recurrent care proceedings in England [2]. The authors concluded that repeat appearances were far from infrequent in the family courts, with one in every four mothers returning to court. In addition, the authors reported broad findings from the case file and qualitative interview component of this study, which have provided insights into the experiences of mothers who appear as respondents in successive sets of care proceedings. Prompted by continued national and international interest in the challenges of engaging parents effectively in preventative services to break a cycle of repeat involvement in the family courts [1-4], in this article we revisit birth mothers' first-person accounts with the aim of offering new insights that help explain why parents may not readily engage 
with professional help. Drawing on the literature on complex trauma [5-7], we focus specifically on women's accounts of the childhood antecedents, which may set in motion mistrust of professionals and, indeed, broader complications in adult interpersonal relationships.

In our previous reports, we have already published findings regarding the concerns that professionals listed as 'major contributing factors' in local authority decisions to issue care proceedings. Parental "non-engagement" was the most commonly cited concern-central in social workers' chronological accounts and formal statements to the court [1]. For reasons largely unexplained in local authority case files, parents were described as resistant to help from a range of preventative services. In this article, we argue that the explanation for this 'resistance' lies-at least in part-in women's own developmental histories. Starting from the premise that early adversity, including persistent exposure to harm or neglect from caregivers, can have a major impact on the capacity to form and maintain interpersonal relationships, our lens in this article is focused on the evidence women shared across interviews about their own relationship experiences.

The paper begins with an exploration of the literature on parental non-engagement in child protection. In the second section of this article, we introduce the reader to the concepts of complex trauma and epistemic trust, arguing that our understanding of parent-professional engagement dynamics is enhanced when we draw on these theoretical frameworks. In the main body of the article, we then revisit qualitative interview data drawn from birth mothers' own accounts of their childhoods to evidence women's early exposure to multiple adversities, including in their caregiver relationships. Further extracts from women's first-person accounts are presented to help demonstrate how these early experiences may help to explain the difficulties women encounter as parents in their relationships with professionals within a child protection context.

To conclude, our recommendations are that received understandings of 'non-engagement' require substantial revision, within both the social work literature and professional practice, if help is to reach more parents with histories of persistent adversity and exposure to harm from caregivers. Problematic parent-professional dynamics cannot simply be equated with intentional acts of resistance on the part of parents-the underlying aetiology is insufficiently explained when parents' motivations are cast in this way. When we apply learning from the literature on complex trauma, resistance can be viewed as an adaptive response where childhoods have instilled little confidence in the capacity of others to meet their dependency needs. Working with parents who have histories of complex trauma requires a highly informed approach, with practice attuned to the developmental roots of parents' difficulties.

\subsection{Non-Engagement in Social Work}

The importance of achieving effective working relationships with parents in the context of child protection concerns remains a fundamental objective in the UK. Similarly, the challenges of working with families in situations where they may be reluctant to receive support or intervention has also been discussed widely and from a variety of perspectives, within the extant literature [8-13]. Through the findings of a series of Serious Case Reviews, professionals working in this difficult terrain are reminded of what happens if they fail to remain child-focused [14]. However, a large body of international literature suggests engaging parents is crucial in achieving change in problematic parental behaviour, which is often a central concern about the well-being of children [15-21] Furthermore, studies suggest that parents' experience of these services is often dependent on their relationship with their social worker. Despite this evidence, achieving cooperative working relationships through skilled professional practice is complex and often proves elusive [22,23].

Whilst the issue of non-engagement is helpfully framed within some literature as a shared responsibility between parents and services [24], in practical terms, responsibility for a breakdown in engagement is most commonly attributed to parents, as evidenced in statements to the family courts in care proceedings [1]. Indeed, successive studies suggest parental engagement makes a significant contribution to decisions regarding coercive action $[15,25,26]$. 
The issue of 'non-engagement' appears in different guises within descriptions of work with parents in child protection, and parental reluctance to engage with state services has been examined from a variety of perspectives. However, inconsistent and shifting use of language adds to the complexity [12,27]. For example, 'resistant', 'hard to reach', 'disguised compliance' are all concepts that, though different, share to varying degrees the notion of parents who are resistant to working collaboratively with services $[10,12,27,28]$. Indeed, the manner in which 'colloquial terms' [27] become embedded in professional discourse can lead to practice that serves to further entrench suspicion and power imbalances between parents and professionals.

There is a body of evidence identifying the professional skill set required to promote parental engagement in the context of child protection. These skills range from core professional competence-providing information, communicating the purpose of agency involvement, responding in a timely manner $[20,25,29,30]$ — to more advanced skills of working collaboratively, demonstrating good authority, and developing shared goals [19,20,31,32]. However, the most consistently cited behavioural determinant of successful engagement is the worker possessing advanced communication skills, skills that epitomise the Rogerian qualities of active listening, empathic understanding, congruence, honesty and respect $[18,20,25,29,30,33,34]$, a capacity to work in a strengths-based way [17,35], and relationship-building skills [32,36].

Despite the importance of this highly skilled and nuanced practice, as Ferguson [8,37] argued, research focusing on work with families where there are safeguarding concerns often fails to capture what happens in the interactions between social workers and families. Yet it is in this space that the most significant work takes place. Indeed, the challenge is to both feel and demonstrate ongoing empathy for parents at times of anxiety, high pressure and conflict. To work sensitively with the sometimes overwhelming, affective response of parents, professionals must be equipped with the skills to work with deep-rooted feelings of distrust and defensiveness [36,38-41]. Yet studies suggest that these skills have been found lacking in child protection social work practice [22]. Thus, whilst Hothschild's concept of 'emotional labour' is helpful in understanding the intensity of child protection social work [42], it may not on its own provide a sufficient enough explanation of the nature of this 'work' and, more importantly, why parents might present as difficult to help.

Clear research findings on the factors underpinning parents' struggle to engage with child safeguarding processes is limited [24], partly due to the complexities of disentangling causality [43], variation in what underpins engagement in different cases [8], and the interaction of parental factors with social workers and the systems they operate within [44]. What might be called the underlying aetiological factors affecting parental engagement include social adversity [45], parental attachment insecurity [10], a response to the stress of the process [46], and parental psychopathology [24]. Platt's integrated, ecological model of parental engagement is helpful in that it draws on the above factors among others in helping practitioners consider the background conditions that may lead to problems with engagement [24].

Turney's [12] important contribution reminds us of the importance of balancing, 'the intra-psychic' and the social/political worlds, and of the connections between the two. Drawing on Howe, she emphasised that an individual's social understanding and competence is dependent upon their relationship history. It is an understanding of this relationship history and its impact that we now wish to turn.

\subsection{Complex Trauma and Epistemic Trust}

Complex Post-Traumatic Stress Disorder (C-PTSD) was recently added to the World Health Organisation's International Classification of Disease (ICD-11). It contains the core features of PTSD: re-experiencing of trauma, avoidance of trauma reminders, persistent hypervigilance, and three additional symptom clusters [6]. These are described as 'disturbances in self-organisation' and comprise emotional dysregulation, negative self-concept, and disturbances in relationships [47]. The term complex trauma is used in this paper to describe features of the C-PTSD diagnosis whilst also 
recognising that it is not possible or desirable to make any classifications of these mothers' experiences based upon qualitative interview data. Whilst C-PTSD is a psychiatric classification, the broader term complex trauma has emerged in part from survivor groups of women campaigning for a mental health descriptor that accurately captures the difficulties that emerge in the context of ongoing interpersonal harm [48].

Complex trauma is caused by chronic and multiple exposures to forms of interpersonal abuse [6] and is likely to be associated with childhood adversity, as maltreatment during childhood is difficult to escape [7]. Different forms of childhood abuse are seen to have differential effects on subsequent complex trauma profiles, with childhood sexual abuse being most strongly associated and women being more at risk overall of developing a complex trauma profile [7].

What is of particular importance for parents subject to child protection interventions is that these 'disturbances in self-organisation' include difficulties that would likely make engagement with professionals challenging. Disturbances in relationships arise in the case of complex trauma because of the interpersonal nature of the traumatic injuries [7]. Early relationships characterised by abuse are likely to lead to long-term issues with relational trust [49]. This results in finding challenging interpersonal interactions difficult to tolerate because of high levels of affect associated with these exchanges. From a parental perspective, demanding and anxiety-provoking interpersonal interactions describes much of their contact with social workers in child protection systems [46,50]. A scoping review of literature regarding parenting after a history of child maltreatment [51] found that traumatised parenting coping strategies included PTSD fight, flight, and freeze responses to perceived threat, which impacted upon relationships with infants, partners, and professionals. Furthermore, the review supported other evidence of problems with engagement arising from a lack of trust in relationships with perinatal care professionals in the context of parental trauma [52].

In a study examining the recovery experiences of mothers with mental illness [53], women reported that it was not the mental illness itself that caused parenting problems but the underlying interpersonal traumas that gave rise to it. They identified that repeated traumas had impacted their ability to relate to others, risking intergenerational transmission of trauma to their children [52] and relationships with professionals [36], and the conclusions drawn were that any interventions needed to be trauma-informed and avoid re-traumatisation in the service system.

A potential psychological mechanism that helps explain how childhood trauma can lead to difficulties in interpersonal relationships in adulthood is epistemic trust. Epistemic trust can be defined as "the ability to appraise incoming information from the social world as accurate, reliable and personally relevant, allowing for the information to be incorporated into existing knowledge domains" [54]. The model of epistemic trust has been developed from the theory of natural pedagogy [55] and is said to emerge in the context of early relationships. Epistemic vigilance is a developmentally necessary strategy to self-protect against external information that may be inaccurate, deceptive, or damaging [56]. Epistemic vigilance is suspended when the child is presented with cultural knowledge that comes from a credible source, in the first instance, a primary attachment figure and, later, other forms of authority figure, such as teachers [57]. In the context of childhood maltreatment such epistemic trust fails to develop, as ongoing vigilance and active mistrust remain necessary, leading to limitations in social learning and a rigidity in holding onto beliefs about others [58]. Furthermore, in the context of interpersonal trauma, the social contract of abiding by the rules is broken for the child by transgressions or neglect by adults, and the rubric of survival becomes dominant over social acceptability. This lack of epistemic trust and emphasis on survival over rule-bound behaviour in traumatised parents is one mechanism that can help explain difficulties in trusting professionals' advice and refusing to follow rules from authority figures, leading to non-engagement.

Low levels of epistemic trust have been proposed as a significant barrier to engaging in psychological treatment [56] and have been found to be associated with a range of attachment and maltreatment problems, leading to mental health problems in adulthood [57]. Given that mothers who experience recurrent care proceedings, with respect to their children being taken 
into care, have experienced a range of relationship difficulties with some combination of their children, key professionals, partners and, often, childhood carers [1], this population is key to understanding parental engagement as it can illustrate what happens when it goes wrong. Drawing on the complex trauma literature and considering the mechanisms of trauma histories alongside patterns of non-engagement may help augment existing models of engagement in the field of child protection.

\section{Materials and Methods}

\subsection{Overview}

For the purposes of this paper, we revisited the qualitative data that formed part of a mixed methods study conducted between 2014 and 2017 [1]. This national profiling study comprised three data sets: Data set A, an analysis of population-level data held by the Children and Family Court Advisory and Support Service (Cafcass); Data set B, 72 semi-structured interviews with birth mothers who have experienced recurrent care proceedings; and Data set $C$, emanating from a detailed study of the court records of 851 sets of proceedings relating to the children of a representative sample of 354 recurrent mothers who had a history of repeat proceedings (referred to here as case file study). Full details of the study and its findings can be found in the published report and associated papers [1,2,4,49,59].

The project was subject to ethical scrutiny by (Lancaster University REC Reference S2014/169). The local authorities supporting participant recruitment were selected with the aim of achieving 'maximum variation' in the participants recruited [60].

Prior to the commencement of data collection, the study was also scrutinised by each participating local authority's internal research governance process. A project protocol was developed with each participating agency that outlined agreed processes for the recruitment of women, and mechanisms for post-interview support were detailed. Recruitment to the study was informed by principles of voluntarism as outlined by the British Sociological Association [61]. Women were recruited to the study by social workers and family support workers within the local authority and third sector partner agencies. The relevant workers were fully briefed prior to recruitment. The criteria for inclusion were as follows: the mother had experienced two or more sets of care proceedings or was currently pregnant, had previously appeared as a respondent in care proceedings, and was currently open to children's services for a pre-birth assessment. The women's capacity to consent to inclusion was an important consideration, and women who had previously required the services of the Official Solicitor within care proceedings were not included. Our initial target for recruitment was 50 women. However, we had also taken a decision that any mother volunteering to be interviewed and meeting our inclusion criteria would not be refused an interview, and, as a result, the final interview sample was 72 .

A two-stage consent process was developed. Initial information about the project was first shared with each potential participant via a known and trusted professional from the participating agencies. This stage included the sharing of an initial information sheet with the mother and, prior to gaining consent, the recruiting professional was asked to consider with the mother the potential emotional impact on the mother taking part. Prior to each interview, the mother was offered an opportunity to speak with the researcher in detail about the study and to clarify any issues. A second stage consent form was completed prior to the interview commencing. This included permission to audio record the interview. Careful attention was paid to explaining the interview protocols, including how women could withdraw from the study and the preservation of anonymity.

Given that women were recruited through agencies, it was likely that we missed some women, who, at the time of this study, were not involved with services at all and perhaps the most difficult to 'reach'. In addition, this sample was of women who were involved in repeat care proceedings, and therefore findings could not be generalised to the broader population of women involved with Children's Services or with the family courts. However, given that one in four mothers are at risk of return to court following child removal and experience further care proceedings, it is vital to continue 
to build the evidence base specific to this population of mothers, who comprise a sizeable proportion of women in care proceedings.

\subsection{The Interviews}

The interviews were semi-structured according to a topic schedule developed by two of the authors. The lead researcher, a qualified social worker with extensive experience of research on people with lived experiences of social work involvement, carried out all the interviews. The interviewer approached the interview as an empathic listener, attentive to the importance of conveying listening and understanding [62]. The interviews varied in length (12 $\mathrm{min}$ to $3 \mathrm{~h} 13 \mathrm{~min}$ ) but were typically of 90 min duration. All interviews were conducted in a private room in either a local authority or partner organisation's premises. The venue was negotiated with the mother in advance to ensure that her wishes were closely considered. Women were offered support with transport to and from the interview. In addition, every woman was offered a GBP 20 high street voucher as recognition of the time given to the study. Upon completion of the interviews, all audios were fully transcribed verbatim and uploaded to NVivo software package for storage, and to enable analysis.

\subsection{Analysis}

During the completion of the substantive study [1], the interviews were analysed individually, prior to common themes being identified across the sample. During an initial round of coding, a large number of open codes were developed. The authors (Mason and Brodhurst) worked together to review individual transcripts and check consistency of interpretation. Early comparisons of these codes enabled commonalities among interviews to emerge, and provisional themes developed [60,62,63] before condensing and rationalising the data around core themes. Decisions about core themes resulted from our observations of the highly consistent statements, messages, or content in the women's first-person accounts $[60,63,64]$. Analytic memos captured throughout the analysis also aided the final reduction to specific core themes. Findings were also discussed with a small group of women who participated in the study to ensure they resonated with women's own interpretations of their experience.

For the purposes of this article, the authors, including Taggart, who brought a clinical lens, revisited specific themes relating to the women's developmental histories, engagement with professionals, and adult interpersonal relationships. Having previously considered the issue of complex trauma in earlier publications [1,49], we subjected the data to further analysis to probe in detail its richness, informed by the conceptual frameworks of complex trauma and epistemic trust, as outlined above. Integrating the different lenses of the academic and clinical analytic team, this article aims for a much deeper and focused understanding of the interaction between the women's developmental histories and their adult engagement and relationship difficulties, as described in the women's own words.

Inevitably, in presenting data to evidence our claims, we drew on selected extracts from the accounts of the 72 mothers participating in the study. However, the extracts we used were selected on the basis of their typicality and after agreement among the authors that the selected extracts best represented the core themes.

\section{Results}

\subsection{Descriptive Profile of the Interview Sample}

As detailed in Table 1, the majority of the women interviewed had become mothers in their teenage years; $79.2 \%$ were 19 or under at the birth of their first child. As will be detailed through their own accounts below, women in the study had experienced considerable hardships in their own childhoods; $59.7 \%$ reported having experienced physical abuse as children, and $47.2 \%$ reported having been sexually abused. Nearly half $(45.8 \%)$ had been in state care. Their difficulties extended beyond childhood, with many experiencing substance misuse difficulties (59.7\%) and mental health problems 
(83.3\%). Problems within intimate adult relationships were stark, with $87.5 \%$ of women reporting having experienced domestic violence.

Table 1. Descriptive profile of interview sample.

\begin{tabular}{|c|c|c|}
\hline $\begin{array}{c}\text { Geographical Location (At Time } \\
\text { of Interview) }\end{array}$ & Number of Mothers Recruited & $\begin{array}{l}\text { No of Local Authorities } \\
\text { Participating in Recruitment }\end{array}$ \\
\hline North West & 29 & 3 \\
\hline Midlands & 26 & 1 \\
\hline London & 17 & 3 \\
\hline Mother's Ethnicity & Count & Percentage \\
\hline White & 62 & 86.1 \\
\hline Black & 5 & 6.9 \\
\hline Other & 5 & 6.9 \\
\hline \multicolumn{3}{|l|}{ Childhood Experiences } \\
\hline Looked after by state & 33 & 45.8 \\
\hline Domestic abuse & 32 & 44.4 \\
\hline Physical abuse & 43 & 59.7 \\
\hline Sexual abuse & 34 & 47.2 \\
\hline \multicolumn{3}{|l|}{ Adult Experiences } \\
\hline Domestic abuse & 63 & 87.5 \\
\hline Mental health issues & 60 & 83.3 \\
\hline Substance misuse issues & 43 & 59.7 \\
\hline $\begin{array}{l}\text { Mother's age at birth of first } \\
\text { child }\end{array}$ & Count & Percentage \\
\hline Under 16 & 9 & 12.5 \\
\hline $16-19$ & 48 & 66.7 \\
\hline $20-25$ & 13 & 18.1 \\
\hline Over 25 & 2 & 2.8 \\
\hline Number of children (live births) & Count & Percentage \\
\hline Two & 17 & 23.6 \\
\hline Three & 22 & 30.6 \\
\hline Four & 16 & 22.2 \\
\hline Five or more & 16 & 22.2 \\
\hline
\end{tabular}

\subsection{Childhood Adversity and Complex Trauma}

As discussed within earlier publications from this study [1,49], a key theme within the interviews was the high levels of maternal childhood abuse and maltreatment. Without exception, all 72 women in the interview sample described multiple adversities that, for most, could be traced to their childhoods. Whilst the impact of early adversity appeared minimised by mothers in a small number of cases, most were able to clearly articulate both difficult early experiences and their resultant vulnerabilities.

We begin with an extract from the interview with Gemma, whose childhood was dominated by experiences of sexual and physical abuse perpetrated by her mother and stepfather. She described her childhood as 'just horrible'.

I was sexually abused (by my stepfather) as a child, and to blank it out I started taking heroin ... Me and mum's never had a proper mother/daughter relationship. It's always been fisticuffs and knocking 
each other out, and throwing plates at each other. She's wacked a frying pan round my head after she's just used it, and I've got a big scar down my head where she's smashed my head off a wall ... My childhood was just horrible ... (Gemma)

Lydia described similar experiences of living in fear of her stepfather, who sexually abused her from the age of 2 to 13 .

Because I've been under social services before I had both of my children because I got sexual assaulted when I were young and I've been through it ... Yeah and it were horrible ... My mum were beaten up every day. Me and my sister saw it every day. She's got no teeth or nothing. She used to get stamped on ... I used to run off after, because I was scared of going home. (Lydia)

Gemma and Lydia's traumatic experiences were not uncommon; $47 \%$ of the women in the interview cohort discussed experiences of sexual abuse in childhood, whilst $59 \%$ experienced physical maltreatment. Accounts of witnessing domestic violence and other forms of emotional harm and neglect were common threads throughout the women's childhood memories.

In the face of threat and fear, children turn to their main caregiver for protection. A secure attachment to a reliable and available caregiver can indeed mitigate against the psychological harm of even the most frightening experiences. However, when absent and, even more damaging, when the caregiver is the source of the fear and harm, then this likely undermines the child's primal drive to seek safety through interpersonal relationships.

Across the interviews, the women's childhood accounts were characterised by multiple adversities, and a lack of felt emotional security was evident. Lisa detailed chronic neglect in her relationship with her mother.

But I mean when I was little my mum used to ... like I say, she used to go out with a lot of men drinking a lot and things. And sometimes she wouldn't pick me up from school so I'd be the last one in school and so teachers would be going home and they'd have to ring social services to come and pick me up, or the police, and I'd be at the police station waiting for my mum for hours. And then other times I used to take maybe her watch or her earrings to school with me, because I knew if they meant something to her and she was missing them and she wanted to go out, she'd come and collect me for the watch or the earrings. (Lisa)

The experience of neglect and abandonment described here led Lisa as a child to go to extreme lengths to get looked after. Her behaviour suggested a deep-felt insecurity, believing her mother prized her jewellery more than Lisa herself. Accounts that illustrated the absence of a reliable and trustworthy authority figure were consistent across the data set. This may have led many of the women to develop low levels of epistemic trust, making it more challenging for future engagement with other authority figures, including professionals. In the absence of a trusted caregiver, who can provide reliable social knowledge enabling the child to navigate her social world, ongoing epistemic vigilance is an adaptive strategy for survival, but it means that other authority figures will elicit similar levels of suspicion, making useful social knowledge more difficult to integrate [56].

\subsection{Secondary Victimisation}

In many cases, women were able to articulate how the lack of a protective caregiver relationship then rendered them vulnerable to a host of adolescent risks $[65,66]$. An example is given in this extract also from Lisa's transcript.

What happened was when I was 14 or 15 I got into a relationship with a man really older than me, he was 42 ... I didn't even know he was 42 to be honest, it was just a case of, oh gosh, someone's took notice in me and this has never happened really. And he started hitting me really early on, he was really controlling, he took all my money off me ... And I fell into the thing with, well, I want to see as 
much of you as I can because I don't see my mum and very rarely have anything to do with anyone else ... because I was so vulnerable and I was so like I don't want to fall into something like this, but I want someone to notice me and I want someone to love me. And that's why I gelled with him so quick I think. (Lisa)

Lisa clearly made connection between her own childhood experiences of neglect and emotional abuse and the abusive relationship she experienced in her teenage years. Similarly, Rhona explained how her vulnerability as a child led to her being groomed by an older man and subsequently to her first two pregnancies:

I was around one (year old) when my parents split up. I was sexually abused by my grandad twice ... I was actually removed from my mum myself due to the fact my mum wasn't able to cope with my sexual abuse. I was removed for two years from my mum, and she fought and then got me back. My mum had depression really, really badly. So I wouldn't say she was a bad mum, but with her depression she wasn't the way some mums would be. I used to find my mum crying mainly all the time, you know. So I wouldn't say it was a brilliant childhood for me ... And then I was in a relationship at 14 with a bloke, but he was older than me, so I was groomed when I was younger. He was an alcoholic. When I had my oldest, he became very controlling. It was, like, you've got my baby, so you'll do as I say. (Rhona)

In this excerpt, we saw an account containing multiple forms of interpersonal childhood adversity: sexual abuse within the family and in an adolescent relationship, neglect, living instability, parental mental health problems, and being in a controlling relationship. Growing up while dealing with multiple forms of harm can lead to a cumulative impact on health and well-being, including making future interpersonal relationships more difficult to navigate [67].

\subsection{Instability and Abuse in Adult Intimate Relationships}

The lack of consistent care and abuse that featured in women's own childhoods was frequently mirrored in their descriptions of their adult relationships. Problematic relationships were an enduring feature of their lives, typically marked by high levels of conflict, violence, and coercion. Indeed, within the interview sample $88 \%$ of women described themselves as being victims of domestic violence, and this was typically across multiple intimate relationships. Frequent relationship breakdowns and quick subsequent relationships were a common pattern. Pregnancy very early into a new relationship was also a common feature of the women's lives.

When viewed through the lens of complex trauma this was unsurprising. The women's own accounts of their histories suggested that a large proportion of those interviewed were likely to experience psychological and interpersonal difficulties that fit a complex trauma profile. The abuse of trust in childhood and experiences of trauma in the context of relationship interdependence are likely to lead to an adaptive strategy that centres on the need to self-protect. This may manifest in different ways in adulthood, dependent upon the childhood experience, but, whilst adaptive in managing childhood adversity, it is unlikely to be helpful in forming and sustaining adult relationships, particularly those where epistemic vigilance needs to be lowered so new forms of social learning can happen. Some of the women were able to make clear links between their childhood adversity and choices surrounding intimate partners. In the extract below, Wendy described how her vulnerability, resulting from childhood abuse and lack of any consistent care, left her vulnerable to a controlling and violent relationship and lacking any escape route once it had become abusive:

About six months, I was in the relationship. And then when I fell pregnant ... He kept hitting me telling me I was ugly,"no wonder your mum and dad didn't like you". And because he was the only one I had, I tried to hold on to him for a long, long time. Because I never had any family to go and talk to. (Wendy) 
Similarly, Holly described how her experience of living with a violent stepfather made her vulnerable to domestic violence as an adult:

My mum and dad split up, apparently there was domestic violence between my mum and dad but nothing has ever been found in social care records, or police records, so I don't know how true that is. But, my mum put my sister and me into care, and my dad had my brothers. We went into care when we were two and my mother got us back when we were four. At that point she was with a new man and pregnant with my stepsister, but basically my stepdad, who she is still with now, used to hit me with belts ... Well, it was clear that my mum chose partners over her children, and growing up I thought that violence was right and I've been with quite violent people. (Holly)

Here, Holly described a familial pattern whereby violence has become normalised and the patterns of abuse that characterised her childhood have influenced her relationships in adulthood. This is an important factor in considering a complex trauma profile as evidence suggests that survivors of childhood maltreatment are at elevated risk of re-victimisation across the lifespan [68].

In this extract, Leanne, a mother of seven children, all removed from her care, reflected on how her own difficult childhood led to her having quick succession pregnancies.

With my first one I was married to a soldier and there was domestic violence and I was young. I got married at 18 and so I wasn't sure how to look after the child properly from my childhood experiences ... My dad used to beat me up all the time, hit me, kick me. They used to make me do all the housework and ... I used to go to work and they used to take all my money off me to pay the bills and that. I ended up pregnant and it was either stay at home with my parents and carry on getting abused, or marry the soldier and move away, so I chose to get married and move away from my family ... and at the end of the day, like all the shit I went through with my family, it was like that only people that you felt ever loved you was your kids. You know? So ... the more kids I had the more people I had that would love me. (Leanne)

Leanne described a series of complex relationships whereby violence again was normalised, she experienced multiple forms of interpersonal abuse in both childhood and then adult relationships, and this appeared to have influenced her future relationship patterns. What was particularly noteworthy was that Leanne dealt with the lack of loving relationships by having children, an understandable response to abuse that, paradoxically, left her more vulnerable to having them removed from her care as she became overwhelmed with the demands of caregiving. Finding adaptive solutions to survive childhood abuse in ways that make sense from the subjective experience of the survivor, whilst appearing maladaptive and socially unacceptable from the outside, is a common feature of a broad range of people with complex trauma [5].

\subsection{Relationships with Professionals}

When considering the issues of non-engagement, women's narratives regarding their interactions with professionals with respect to child protection concerns gave us the greatest insights. Within the interviews, women spoke candidly about their experiences of professional interventions. Given the population under discussion here, it was unsurprising that these were largely centred on their interactions with their child's social workers and mostly seen as negative. When viewed from the perspectives of the women's own trauma histories, their accounts contained important commonalities, which coalesced around three central themes, detailed below.

\subsubsection{Re-Victimisation, Mistrust and Judgement}

As is illustrated by the excerpts included here, poor levels of trust between professionals and the mothers commonly led to a pervasive feeling of judgement that was counterproductive in enabling the development of a strong working relationship on which engagement could be built. Because of 
the women's trauma histories this communication pattern of judgement and criticism was likely to evoke earlier patterns of relating in other coercive relationships, leaving the mothers feeling bullied and denigrated. Below, Leanne described feeling persecuted and intruded upon in her relationship with her social worker and slipping quickly into feeling overwhelmed by a barrage of information, a key feature of trauma responses to interpersonal difficulties [49].

They told me stuff but I've never really understood what they say to me. The way that I see it is they come into your house, yeah, complain about all the things you're doing wrong, make you feel shit, and then they go. And then you try and do good stuff but they never say anything that you do right and you just feel like you're being bullied all the time. And then that makes you feel shit and then you don't want to do nothing. You think, well what's the point, because they don't notice anyway? (Leanne)

The excerpt served as an important reminder that there is an underlying awareness of class, and social hierarchies can also underpin problematic parental/professional relationships in child protection, a feeling described by Yasmin here and supported by research that demonstrated much higher levels of referrals in more disadvantaged communities [45].

And then when you come into buildings like this there's very few staff that actually make you feel like you haven't done anything wrong. The rest of them just look down their noses at you and make you feel like you're a bit of shit on the bottom of their shoe... No, don't get any support and understanding off the social workers, you don't. They look down their nose, through their pedestals, looking at people as if to say, you know what, because I live on a council estate and I'm on benefits... I was on benefits at that time. (Yasmin)

Whilst this feeling of being blamed and judged was not specifically about childhood adversity, it illustrated a pervasive pattern of judgement and intrusive blame experienced by the women in a broad range of their lives, including intimate relationship history, childhood abuse, and social class. All of these forms of blame served to create an interpersonal context where epistemic trust continued to be low, making engagement more challenging.

The experience of feeling judged was central to many of the women's accounts. For many, they felt that it was impossible to meet the expectations of their children's social workers. This left women feeling demoralised and, for some, was key to them 'giving up' and disengaging. For others, the effect on their mental health was profound. Brodie described the extent of her anxiety when she was undergoing parenting assessment following the birth of her son.

It really was the most messed up time of my life, worse than the abuse, because I couldn't even ... I didn't know if I really was acting nuts or if they was just brainwashing me by reading the reports about myself. Because I was thinking, I'm not this person or am I? I might have had anger problems and that, but if you look at my history, it's not like I've beat loads of people up. You know, I've been arrested for a few robberies..., but it's not like I've gone out there and battered people and hurt people. Yeah, so I started believing, you know, I can't do this, I'm not a good mum, I don't know how to be a mum, because I'd heard it so much that I thought I can't do this, give him to his Nan. (Brodie)

The profound impact of the system on Brodie's mental health was clear in her account. Key here was that she described the experience of engaging with professionals and seeing their judgements of her as 'worse than the abuse.' This led to another theme common within the women's accounts: re-traumatisation occurring through contact with professionals.

\subsubsection{Re-Traumatisation, Shame and Blame}

When asked about their relationships with services, the women commonly described that they felt blamed for the difficulties they experienced in their own childhood adversity, and now that they were 
parents they were being 'punished' again. They had gone from being seen by the system as 'victims' to 'villains', somehow tainted by their past. The shift from experiencing abuse in childhood to having that abuse used to criticise their own parenting is an example of 'victim blaming', a common theme in trauma survivors' accounts of re-traumatisation. The blaming for harm being caused to the victim by the perpetrator was a central feature of the original abusive relationships [20]. Brodie, herself placed in care following a history of neglect and sexual abuse perpetrated by her father and uncle, described how she felt when children's services initiated proceedings and placed her and her newborn in a mother and baby assessment unit.

I felt like this is my baby, why can't I be alone with my child, I've never hurt a child in my life. It's not like, you know, I've got a mark against my record for hurting children when I was younger or something because I don't, so it was, like, why is that happening, I'm not a paedophile and I'm not a child abuser. It was family history ... I felt like I was being punished for the sins of my father. (Brodie)

Similarly, Lydia described how she felt when her history, combined with her being a 'young mum', led to her being victimised by Children's Social Care.

The only thing ... they look at you to find out about your lifestyle, is if you've been ... had a rough life yourself, they bring all your lifestyle up from when you were younger.... All us young mums are getting bullied for something we've not done. I've never hit a child in my life, I've never done anything to a child, even to harm them or hurt them. All I wanted is a chance to be a mum. But it ain't going to happen ... I think they're using my past against me ... They say I'm a risk to children because of my lifestyle. If I didn't go through what I went through when I were younger myself, they (my children) would have been at home. (Lydia)

Frankie also explained how she felt when her own experiences of abuse led to the decision to remove her baby from her care. The injustice she felt at this pre-emptive action was clear and left her with profound feelings of anger.

It was horrible, because they never give me a chance because I said to them, I see lots of parents out there that's hurt their children and ... and there's me that's wanted a chance to prove to them that I could parent and they've just throwing it back in my face... But if you don't give a person a chance with a child, then they're not going to learn. I understand if a person's hurt a child, then that's fair enough, but don't judge someone just 'cause it's on paper when they've just had a baby. It's not right ... (Frankie)

In the extract below, Laura also described how she felt that her past was being 'used against her', a common thread in the women's accounts and an indicator of victim blaming and re-traumatisation.

They'd bring up my past and stuff, because I was raped when I was younger and it does make you feel punished. I think other mums that have been through it would say the same as well. They do make you feel like you're in a fishbowl and suffocating, and you can't work with them because they're too full on sometimes. But if you tell them that they're too full on it goes against you, and you're scared what to say and what to do around them because you think they're going to constantly keep taking your kids off you. (Laura)

This mother's struggle to tell services what they wanted to hear could readily be constructed within the professional discourse of disguised compliance [20], but when viewed from a perspective of complex trauma, a different understanding may emerge. This is a dynamic based on 'power over' relationships, which are a core feature of complex trauma histories [7]. The experience of re-traumatisation is a significant issue for patients in the psychiatric system when there are operating principles of coercion and control [69]. Child protection proceedings can be similar for parents in 
that they are often required to engage, and this can demand painful recollections of historical trauma. Whilst this history-taking is necessary, for both Laura and Brodie it was experienced as abusive and resulted in actions they perceived as punishment, irrespective of intention. Gina described a similar experience.

I'll say it how it is. She was a complete and utter bitch that used everything personal I told her against me instead of helping me. She went through my entire childhood, went into complete detail about my abusive relationships. ... Everything she could find she took to court and she threw at me instead of saying, well you've been through this, you've been through that, what can we do to get you past it? There was none of that. There was ... it was all just, no, you're not safe. (Gina)

Given the previously discussed elevated probability of repeat re-victimisation, it is important to recognise that whilst parental childhood history is relevant to assessing current risks to children, it is the way in which this history is taken and how that information is subsequently used that matters. As the mother in the excerpt above illustrated, parents themselves are often left with a sense that their history has been used against them, rather than being offered empathic support.

\subsubsection{Epistemic Trust and Responses to Perceived Threat}

Lack of trust was common across the women's descriptions of their involvement with services. Across the interviews, women gave specific examples of interactions in which they felt trust was broken. In many cases, this then quickly escalated to feelings that the worker and the system more generally were deliberately conspiring against them.

In the extract below, Michaela described how quickly she felt trust was betrayed. She described how bringing a social worker and a doctor to her house, when she was expecting a counsellor, quickly led to her feeling that the worker was plotting against her.

You see, me and my social worker didn't have a good relationship anyway... From when I was pregnant with (child2) ... she was going to me, "I'll bring a counsellor to your house to help you", she didn't bring a counsellor to my house, she brought a doctor and a social worker to my house. And that was the beginning of the end of our relationship ... once you've lied you can't go back on it, you can't build your trust especially with someone who's supposed to be there to help you instead of just, f*** you, sort of thing and just do what she wanted, and that's what she'd done, she didn't tell me anything, she just went behind my back and done what she wanted to do. (Michaela)

The low levels of epistemic trust illustrated how quickly the mother felt betrayed by her social worker was an example of how something that from the social worker's perspective may have been a simple miscommunication, in the context of a lifetime of adversity in relationships, could lead to a breakdown in the relationship, increasing the risks of disengagement.

In Laura's accounts of her interactions with Children's Social Care, her lack of trust and fear were clear. She explained that this fear escalated until it became so overwhelming that she disengaged completely and left her children in the care of her mother.

“... Because I was scared because I didn't want to lose them (the children), so I just panicked. But I stopped working, I stopped answering the door to social care, because I never had the kids there anymore, and I was mad at the social worker for disclosing information ... and then they got took out of my mum's care and I never seen them again. I was just going to go to one of the contacts, and my mum had rang me and said social service had took them. (Laura)

Laura refers frequently to feeling 'panicked' and 'scared'. Across the data, women spoke of feeling a sense of overwhelming emotion in their dealings with services; responses marked by fear, panic, and anger, which they found hard to regulate, were common. Whilst this response may be understandable and common to any parent where a powerful state intervenes in their life, a person's 
ability to manage these extreme emotions is likely to be affected by their own histories. Many accounts were characterised by a pronounced lack of trust in others, specifically services, and could be linked to an underlying lack of epistemic trust resulting from their own childhood experiences and repeated victimisation across the lifespan. The struggle to trust other people is a common theme in the lives of complex trauma survivors and can be seen as evidence of a survival strategy to mediate future risk [7]. In this case, the lack of trust between Laura and services led to avoidance of the perceived threat and disengagement, ultimately contributing to the decision to remove her children from her care.

Similarly, Gemma, early on in her interview, described her deep mistrust of children's services:

(D)on't trust social services as far as you could throw them. Never trust them. (Gemma)

Throughout her interview Gemma's descriptions of her encounters with social workers were highly charged; in this first extract she described her reaction when, following an anonymous referral, a social worker made an unannounced visit to her and her baby:

I said, I've been clean for five weeks. I was horrible. I went, there's my door, I said, make sure it smacks your arse on the way out and you get a face plant on the drive. I said, get out. (Gemma)

Gemma recounted similar patterns in her dealings with her social workers throughout her story. Given the punitive and threatening experiences in her childhood, Gemma was likely to be primed for threat and expected the worst from others. Gemma's 'fight' response was easily triggered, like a number of the women in the study when faced with a perceived threat from professionals within children's services. Below, Ingrid explained her belief that because of what she described as 'her attitude and her mouth' she did not receive the support she needed.

(I)nstead of helping me and putting away my attitude, and whatever, and thinking about, yes she's got a bad attitude but she looks after her kids, we'll try and help her keep them, she's asked for help, let's give her help. No, they just didn't like me, didn't like my attitude, they didn't like my mouth, so that was more the reason why they didn't want to help me. (Ingrid)

In each of these accounts, to greater or lesser extent, the woman's reactions to the threat posed by the social worker was to meet it with aggression. An interaction with authority seen as highly threatening to a parent with a history of childhood trauma may be, in the mind of the worker, a routine interaction. In this context, the parent's reaction appears extreme, and they are easily labelled as 'resistant' or 'aggressive'. The strategy that may have been developed as a child to protect herself from an abusive parent becomes maladaptive within the context of a parent within child protection services.

The women's accounts of such encounters acutely demonstrated the importance of workers remaining mindful of the micro-interactions. As can be seen in the extract below from Courtney's interview, ill thought-out comments had lasting ramifications for the women's perceptions of 'the state' and the perceived drivers for those who worked within it.

Yes it's really quite disgusting. Like I was sitting with J the other day and the woman that took my child, I swear to god I'm sitting here and she walked up to me and says, hi how's life? Like that. I'm looking at her just smiling and I really felt to just get up and smack her face off... Why would you come up to me all smiles and how's life, like she's trying to rub it in? ... It's just another child taken off. I'll go with my pay check, that's a bonus. That's how I see it. (Courtney)

A similar perception of the cynicism that pervades the parent/professional relationship could be seen in the extract from Sonya's interview below; for those women in the study who had negative experiences of care themselves, this distrust appeared particularly acute.

I've got five children. But they (Children's Social Care) were already in my life because I was in care, so I think they literally stitched me up good and proper. So, when I had my first daughter they were on 
the scene like that (clicking sound), literally on the scene like that ... There were some times I didn't even answer the door to them unannounced ... and I thought, no, enough's enough, mate, you're not coming in, so I'm not answering the door to you. Then it went against me in court though, didn't it, I can't win ... but I won't have no more because, well, social services' Christmas come at once, our newborn baby up for adoption-yeah-I'm not a baby mother just for them, so it's not happening, no chance. (Sonya)

For Sonya, in care herself from the age of 12, the social workers' actions made her feel like she was being 'stitched up', that they were not there to offer support when she needed it. Her account was one of a number of examples where women felt that there was a conspiracy against them. She likened the idea of having a baby to 'Christmas coming at once' for children's services, believing that they were waiting for her to have a baby so they could remove it from her care and place it for adoption. In a number of accounts, women discussed their belief that social workers received cash bonuses for removing children.

In a different, less defiant form of disengagement, Laura described how, after having previous children removed from her care, she felt unable to seek any help because she believed seeking help might be seen as proof that she was not able to cope.

If I felt down or something I couldn't go to my doctor because I'm too scared that social services would ... They'll put it oh, she's feeling low again on her pregnancy and she ain't going to be able to cope. It makes you feel as though you can't trust anyone. (Laura)

Similarly, Leanne described how her fear that her older children would be removed from her care if she were not at home with them prevented her from seeking medical attention during pregnancy.

I was ill. I had Hyperemesis ... And they said to me another 24 hours I could have died because I was that ill but I was too scared to go into hospital in case social services come and take the kids. (Leanne)

Rosa's account illustrated that her fear of losing her child ultimately led her to her 'giving up' and placing one child in her mother's care whilst taking risks with her own and her unborn child's health.

Obviously I used to get very agitated on the phone and kind of shout and that down the phone because she's not listening to my side of the story ... just weren't coping with everything, with, like, not the social services ... I thought to give up, that time I thought, right, I've got nothing, social services are not on my side, they're not believing what I'm saying, ... and I just felt they were, everybody, was going against me, and I felt, I've lost my daughter, I'm going to lose the court case. So I went a bit on a wild one, and I was drinking during my pregnancy, of which I know that was wrong ... Yeah, I was scared. And then obviously I got more and more depressed, and (daughter) was probably about nine months and I just gave her to my mum, I said I couldn't cope any more, and then gave her to my mum; and went on a wild one for a good couple of months after I've give her to my mum. (Rosa)

Not being able to cope and going on a 'wild one' can be understood as a way to disengage, not only from working with professionals but also from the issues, both historic and current, that led to the need for social care intervention in the first place.

For parents with complex trauma histories, disengagement when relationships become emotionally overwhelming leaves them with some modicum of control in a situation where they otherwise feel helpless. Disengagement from professionals and the use of substances to emotionally numb themselves against feelings of shame and anxiety is a common theme in people with complex trauma profiles [70] and adds to the mutual lack of trust in parent-professional relationships. Escalating cycles of parental risk-taking and hostility to managing complex trauma responses such as emotional dysregulation lead professionals to increase their checking and negative evaluation of parenting. The consequence of these cycles is an increasing breakdown in trust between professional and parent. Thus, disengagement becomes increasingly likely, as does the conditions for the recreation of the parent's childhood 
trauma, in the form of authority figures intruding into the parent's intimate life. This can lead to intergenerational patterns of epistemic mistrust when the removed children become parents themselves, as was the case for a significant number of mothers in this group.

\section{Discussion}

In this paper, we demonstrated how the concepts of complex trauma and epistemic trust help to challenge traditional perceptions of parental non-engagement in child protection services. Drawing on empirical data from a large-scale study of women in recurrent care proceedings we argue that to engage meaningfully with mothers in the context of child protection concerns, professionals must be equipped with the skills and aptitude to consider how a mother's own childhood adversity has affected her ability to relate to professionals. As evidenced in the previously published findings from the case file study and the interview data included here, the majority of the mothers had suffered multiple adversities in their own childhoods [1]. In addition, detailed evidence from the women's childhood accounts suggested that it was likely that many women had psychological and interpersonal difficulties that fit a complex trauma profile. A core feature of complex trauma is that people struggle in relationships and have low levels of epistemic trust. This arises from the fact that trauma has often been experienced in the context of relationships of interpersonal dependence, and that the abuse of trust leads to an adaptive strategy to avoid relational intimacy or to developing ways of managing relationships that prioritise the need for self-protection. Examples of this could be seen in women's own accounts of their adult intimate relationships and, more crucially for the discussion in this paper, in their interactions with their children's social workers. Whilst these strategies were adaptive in managing childhood adversity, they were less helpful to parents in the context of child protection who needed to be able to work with professionals and to demonstrate their ability to take on board and address their concerns about their ability to parent safely. A proposed mechanism to help explain why childhood interpersonal abuse and a trauma response can lead to problems with engagement is via the mechanism of epistemic trust. Low levels of trust in authority figures lead to a rigid style of social learning, where survival overtakes the rubric of rule-based behaviour. Whilst we are careful not to claim a causal link, we propose that the evidence in the qualitative interviews at the very least justifies such a hypothesis. We do not suggest that every parent who has experienced abuse and maltreatment in their childhood has developed complex trauma. Neither do we wish to pathologise parents' understandable resistance to child protection involvement. We are aware of the dangers of a deterministic causal analysis of risk factors and adult health outcomes, and are mindful of concerns that a simplistic interpretation of childhood adversity measures can lead to another tranche of intrusive state-sponsored interventions in marginalised communities [71,72]). Rather, we aim to try to improve the understanding of parental behaviour, and how, by increasing their awareness of the impact of complex trauma, professionals might attempt to engage parents differently and, as a result, increase the possibility of effecting change. We argue that by conceptualising parents with histories of trauma as people who understandably find trust in relationships complex and fraught, then we can move away from non-engagement as illustrative of parental deficit or deceit and begin to understand it as in part an adaptive strategy for survival. Given how embedded childhood adversity is in the wider social context and linked to other forms of structural harm and discrimination [72], it seems helpful to think of understandings of trauma and social adversity as interlinked and complementary, rather than in opposition. Thus, analysis of the links between child protection and social inequality [44,45] can include consideration of the forms of individual adversity and interpersonal trauma that occur in the context of poverty, the reduction of service provision, and subsequent marginalisation. It links the psychological with the social through what we see as central to effective relationship-based social work [36].

Based on the interview data presented, we suggest that complex trauma responses can lead to different forms of disengagement from services that can be understood as adaptive strategies. Bringing a complex trauma lens to professional intervention with parents requires the practitioner 
to pay far greater attention to parents' social histories, and for practice to be more attuned to the developmental roots of parents' difficulties [49]. Crucially, consideration needs to be given to how this same social history affects mothers' ability to engage with professionals. This approach to practice aligns with other recommendations from the wider engagement in child protection and, more specifically, the relationship-based practice literature [36].

We also make a case for professionals working across the family justice system-social workers in particular-to take a trauma-informed approach (TIA) [48] in their attempts to engage effectively with parents in child protection and family court processes. TIAs are systems level organisational interventions, designed to prevent re-traumatisation in treatment settings [48]. More information on what TIAs look like in practice with this population have been discussed elsewhere [73] They prioritise the psychological and physical safety of both staff and service users and attempt to understand the people presenting issues in the light of their trauma history. In therapeutic work, mentalisation-based approaches have been found effective in increasing levels of epistemic trust through the strengthening of relational trust and enabling the person to take on board socially useful knowledge and to loosen rigid patterns of thinking [56].

The focus of this paper is birth mothers. This is simply because the data presented here emanated from a birth mothers study. However, given the findings from a recently completed fathers in recurrent care proceedings study, we suggest that the issues presented in this paper are also pertinent for work with fathers [74] (see also Phillips et. al. in this Special Issue).

Despite widespread acknowledgement of the intergenerational patterns of adversity, an understanding of the issues of complex trauma has not yet had sufficient impact on policy and practice. Ironically, child protection social work is specifically aimed at reducing the risk of this sort of adversity happening to children. What is missing is work to address the impact of childhood adversity and subsequent complex trauma presentation in parents. Whilst it may concern some that this approach will take the focus off the child's welfare, we argue that seeing the child and parent in such a binary way is unhelpful, and that taking a trauma-informed approach is helpful in protecting children by reducing the likelihood of parental disengagement.

Author Contributions: Conceptualization, C.M. and D.T.; methodology, C.M. and K.B.; formal analysis, C.M., D.T. and K.B.; investigation, C.M. and K.B.; writing—original draft preparation, C.M. and D.T.; writing一review and editing, K.B., C.M. and D.T.; supervision, K.B.; project administration, C.M. and K.B.; funding acquisition, K.B. and C.M. All authors have read and agreed to the published version of the manuscript.

Funding: This research was funded by Nuffield Foundation, grant number (KID/41930).

Acknowledgments: This paper draws on data from a large national study 'Vulnerable Birth Mothers and Recurrent Care Proceedings' study. The authors would like to acknowledge the full study research team at The Centre for Child and Family Justice Research, Stuart Bedston, Lisa Morris, Bachar Alrouh, Judith Harwin, Melanie Palmer and Tricia McQuarrie for their contribution in the collection and analysis of the file study data. We also wish to thank Sheena Webb from FDAC London for her contributions which have helped inform our thinking.

Conflicts of Interest: The authors declare no conflict of interest

\section{References}

1. Broadhurst, K.; Mason, C.; Bedston, S.; Alrouh, B.; Morriss, L.; McQuarrie, T.; Palmer, M.; Shaw, M.; Harwin, J.; Kershaw, S. Vulnerable Birth Mothers and Recurrent Care Proceedings, Final Report. Available online: https://www.nuffieldfoundation.org/sites/default/files/files/rc-final-summary-report-v1_6. pdf (accessed on 26 November 2020).

2. Broadhurst, K.; Alrouh, B.; Yeend, E.; Harwin, J.; Shaw, M.; Pilling, M.; Mason, C.; Kershaw, S. Connecting Events in Time to Identify a Hidden Population: Birth Mothers and Their Children in Recurrent Care Proceedings in England. Br. J. Soc. Work 2015, 45, 2241-2260. [CrossRef]

3. Cox, P.; Barratt, C.; Blumenfeld, F.; Rahemtulla, Z.; Taggart, D.; Turton, J. Reducing recurrent care proceedings: Initial evidence from new interventions. J. Soc. Welf. Fam. Law 2017, 39, 332-349. [CrossRef]

4. Broadhurst, K.; Mason, C. Child removal as the gateway to further adversity: Birth mother accounts of the immediate and enduring collateral consequences of child removal. Qual. Soc. Work 2019, 19, 15-37. [CrossRef] 
5. Herman, J. Trauma and Recovery; Basic Books: New York, NY, USA, 1992.

6. Karatzias, T.; Shevlin, M.; Fyvie, C.; Hyland, P.; Efthymiadou, E.; Wilson, D.; Cloitre, M. Evidence of distinct profiles of post-traumatic stress disorder (PTSD) and complex posttraumatic stress disorder (CPTSD) based on the new ICD-11 Trauma Questionnaire (ICD-TQ). J. Affect. Disord. 2017, 207, 181-187. [CrossRef]

7. Hyland, P.; Shevlin, M.; Elklit, A.; Murphy, J.; Vallières, F.; Garvert, D.W.; Cloitre, M. An assessment of the construct validity of the ICD-11 proposal for complex posttraumatic stress disorder. Psychol. Trauma Theory Res. Pract. Policy 2017, 9, 1-9. [CrossRef]

8. Ferguson, H. Performing child protection: Home visiting, movement and the struggle to reach the abused child. Child Fam. Soc. Work 2009, 14, 471-480. [CrossRef]

9. Smithson, R.; Gibson, M. Less than human: A qualitative study into the experience of parents involved in the child protection system. Child Fam. Soc. Work 2017, 22, 565-574. [CrossRef]

10. Shemmings, D.; Shemmings, Y.; Cook, A. Gaining the trust of 'highly resistant' families: Insights from attachment theory and research. Child Fam. Soc. Work 2012, 17, 130. [CrossRef]

11. Turnell, A. Constructive Child Protection Practice: An Oxymoron or News of Difference? J. Syst. Ther. 2006, 25, 3-12. [CrossRef]

12. Turney, D. A relationship-based approach to engaging involuntary clients: The contribution of recognition theory. Child Fam. Soc. Work 2012, 17, 149-159. [CrossRef]

13. Trotter, C. Working with Involuntary Clients, 3rd ed.; Routledge: New York, NY, USA, 2015.

14. Brandon, M.; Belderson, P.; Sorensen, P.; Dickens, J.; Sidebotham, P.; Cleaver, H.; Garstang, J.; Harris, J.; Wate, R. Complexity and Challenge: A Triennial Analysis of SCRs 2014-201; Department for Education: London, UK, 2020.

15. Littell, J.H. Client participation and outcomes of intensive family preservation services. Soc. Work Res. 2001, 25, 103-114. [CrossRef]

16. Lee, C.D.; Ayon, C. Is the client-worker relationship associated with better outcomes in mandated child abuse cases? Res. Soc. Work Pract. 2004, 14, 351-357. [CrossRef]

17. Mason, C. Social work the 'art of relationship': parents' perspectives on an intensive family support project. Child Fam. Soc. Work 2012, 17, 368-377. [CrossRef]

18. Gladstone, J.; Dumbrill, G.; Leslie, B.; Koster, A.; Young, M.; Ismaila, A. Looking at engagement and outcome from the perspectives of child protection workers and parents. Child. Youth Serv. Rev. 2012, 34, 112. [CrossRef]

19. Farrell, A.F.; Luján, M.L.; Britner, P.A.; Randall, K.G.; Goodrich, S.A. 'I am part of every decision': Client perceptions of engagement within a supportive housing child welfare programme. Child Fam. Soc. Work 2012, 17, 254-264. [CrossRef]

20. Schreiber, J.C.; Fuller, T.; Paceley, M.S. Engagement in child protective services: Parent perceptions of worker skills. Child. Youth Serv. Rev. 2013, 35, 707-715. [CrossRef]

21. Hess, P.M.; McGowan, B.G.; Botsko, M. A preventive services program model for preserving and supporting families over time. Child Welf. 2000, 79, 227-265.

22. Forrester, D.; McCambridge, J.; Waissbein, C.; Rollnick, S. How do child and family social workers talk to parents about child welfare concerns? Child Abus. Rev. 2008, 17, 23-35. [CrossRef]

23. Smith, B. Child welfare service plan compliance: Perceptions of parents and caseworkers. Families in Society. J. Contemp. Soc. Serv. 2008, 89, 521-532.

24. Platt, D. Understanding parental engagement with child welfare services: An integrated model. Child Fam. Soc. Work 2012, 17, 138-148. [CrossRef]

25. Platt, D. Congruence and co-operation in social workers' assessments of children in need. Child Fam. Soc. Work 2007, 12, 326-335. [CrossRef]

26. Holland, S. Child and Family Assessment in Social Work Practice; Sage Publications: London, UK, 2010.

27. Leigh, J.; Bedoe, L.; Kendall, E. Disguised compliance or undisguised nonsense? A critical discourse analysis of compliance and resistance in social work practice. Fam. Relatsh. Soc. 2020, 9, 269-285. [CrossRef]

28. Tuck, V. Resistant Parents and Child Protection: Knowledge Base, Pointers for Practice and Implications for Policy. Child Abuse Rev. 2013, 22, 5-19. [CrossRef]

29. De Boer, C.; Coady, N. Good helping relationships in child welfare: Learning from stories of success. Child Fam. Soc. Work 2007, 12, 32-42. [CrossRef] 
30. Maiter, S.; Palmer, S.; Manji, S. Strengthening Social Worker-Client Relationships in Child Protective Services. Qual. Soc. Work. Res. Pract. 2006, 5, 161-186. [CrossRef]

31. Altman, J.C. A Study of Engagement in Neighborhood-Based Child Welfare Services. Res. Soc. Work. Pract. 2008, 18, 555-564. [CrossRef]

32. Forrester, D.; Killian, M.; Westlake, D.; Sheehan, L. Patterns of practice: An exploratory factor analysis of child and family social worker skills. Child Fam. Soc. Work 2019, 25, 108-117. [CrossRef]

33. Yatchmenoff, D.K. A closer look at client engagement: Understanding and assessing engagement from the perspectives of workers and clients in nonvoluntary child protective service cases. In The Carrot or the Stick? Towards Effective Practice with Involuntary Clients in Safeguarding Children Work; Calder, M.C., Ed.; Russell House Publishing: Dorset, UK, 2008; pp. 59-77.

34. Gockel, A.; Russell, M.; Harris, B. Recreating family: Parents identify worker-client relationships as paramount in family preservation programs. Child Welf. 2008, 87, 91-113.

35. Kemp, S.P.; Marcenko, M.O.; Lyons, S.J.; Kruzich, J.M. Strength-based practice and parental engagement in child welfare services: An empirical examination. Child. Youth Serv. Rev. 2014, 47, 27-35. [CrossRef]

36. Ruch, G.; Turney, D.; Ward, A. Relationship-Based Social Work: Getting to the Heart of the Practice, 2nd ed.; Jessica Kingsley: Philadelphia, PA, USA, 2018.

37. Ferguson, $\mathrm{H}$. What social workers do in performing child protection work: Evidence from research into face-to-face practice. Child Fam. Soc. Work 2016, 21, 283-294. [CrossRef]

38. Thoburn, J.; Lewis, A.; Shemmings, D. Paternalism or Partnership? Family Involvement in the Child Protection Process; Her Majesty's Stationery Office: London, UK, 1995.

39. Kemp, S.P.; Marcenko, O.M.; Hoagwood, K.; Vesneski, W. Engaging parents in child welfare services: Bridging family needs and child welfare mandates. Child Welf. 2009, 88, 101-126.

40. Howe, D. The safety of children and the parent-worker relationship in cases of child abuse and neglect. Child Abus. Rev. 2010, 19, 330-341. [CrossRef]

41. Damiani-Taraba, G.; Dumbrill, G.; Gladstone, J.; Leslie, A.; Charles, M. The evolving relationship between casework skills, engagement, and positive case outcomes in child protection: A structural equation model. Child. Youth Serv. Rev. 2017, 79, 456-462. [CrossRef]

42. Winter, K.; Morrison, F.; Cree, V.; Ruch, G.; Hadfield, M.; Hallett, S. Emotional Labour in Social Workers' Encounters with Children and Their Families. Br. J. Soc. Work 2018, 49, 217-233. [CrossRef]

43. Nock, M.K.; Ferriter, C. Parent Management of Attendance and Adherence in Child and Adolescent Therapy: A Conceptual and Empirical Review. Clin. Child Fam. Psychol. Rev. 2005, 8, 149-166. [CrossRef]

44. Featherstone, B.; White, S.; Morris, K. Re-Imagining Child Protection; Policy Press: Bristol, UK, 2014.

45. Bywaters, P.; Brady, G.; Sparks, T.; Bos, E. Inequalities in child welfare intervention rates: The intersection of deprivation and identity. Child Fam. Soc. Work 2014, 21, 452-463. [CrossRef]

46. Buckley, H.; Carr, N.; Whelan, S. Like Walking on Eggshells': Service User Views and Expectations of the Child Protection System. Child Fam. Soc. Work 2011, 16, 101-110.

47. Maercker, A.; Brewin, C.R.; Bryant, R.A.; Cloitre, M.; Reed, G.M.; Van Ommeren, M.; Humayun, A.; Jones, L.M.; Kagee, A.; Llosa, A.E.; et al. Proposals for mental disorders specifically associated with stress in the International Classification of Diseases-11. Lancet 2013, 381, 1683-1685. [CrossRef]

48. Sweeney, A.; Clement, S.; Filson, B.; Kennedy, A. Trauma-informed mental healthcare in the UK: What is it and how can we further its development? Ment. Health Rev. J. 2016, 21, 174-192. [CrossRef]

49. Broadhurst, K.; Mason, C.; Webb, S. Birth mothers returning to court: can a developmental trauma lens inform practice with women at risk of repeat removal of infants and children. In Justice for Children and Families: A Developmental Approach; Shaw, M., Ed.; Cambridge University Press: Cambridge, UK, 2018.

50. Jackson, S.; Kelly, L.; Leslie, B. Parental participation in child protection case conferences. Child Fam. Soc. Work 2020, 25, 421-429. [CrossRef]

51. Chamberlain, C.; Gee, G.; Harfield, S.; Campbell, S.; Brennan, S.; Clark, Y.; Mensah, F.; Arabena, K.; Herrman, H.; Brown, S.; et al. Parenting after a history of childhood maltreatment: A scoping review and map of evidence in the perinatal period. PLoS ONE 2019, 14, e0213460. [CrossRef] [PubMed] 
52. Isobel, S.; Goodyear, M.; Furness, T.; Foster, K. Preventing intergenerational trauma transmission: A critical interpretive synthesis. J. Clin. Nurs. 2018, 28, 1100-1113. [CrossRef]

53. Hine, R.; Maybery, D.; Goodyear, M. Challenges of connectedness in personal recovery for rural mothers with mental illness. Int. J. Ment. Health Nurs. 2017, 27, 672-682. [CrossRef] [PubMed]

54. Orme, W.H.; Bowersox, L.; Vanwoerden, S.; Fonagy, P.; Sharp, C. The relation between epistemic trust and borderline pathology in an adolescent inpatient sample. Bord. Pers. Disord. Emot. Dysregul. 2019, 6, 13-19. [CrossRef] [PubMed]

55. Csibra, G.; Gergely, G. Natural pedagogy. Trends Cogn. Sci. 2009, 13, 148-153. [CrossRef]

56. Fonagy, P.; Allison, E. The role of mentalizing and epistemic trust in the therapeutic relationship. Psychotherapy 2014, 51, 372-380. [CrossRef]

57. Fonagy, P.; Luyten, P.; Allison, E.; Campbell, C. What we have changed our minds about: Part 1. Borderline personality disorder as a limitation of resilience. Bord. Pers. Disord. Emot. Dysregul. 2017, 4, 1-11. [CrossRef]

58. Ensink, K.; Normandin, L.; Target, M.; Fonagy, P.; Sabourin, S.; Berthelot, N. Mentalization in children and mothers in the context of trauma: An initial study of the validity of the Child Reflective Functioning Scale. Br. J. Dev. Psychol. 2014, 33, 203-217. [CrossRef]

59. Broadhurst, K.; Mason, C. Birth parents and the collateral consequences of child removal: Towards a comprehensive framework. Int. J. Law Policy Fam. 2017, 31, 41-59. [CrossRef]

60. Ritchie, J.; Lewis, J. Qualitative Research Practice; SAGE Publications: London, UK, 2003.

61. British Sociological Association. Statement of Ethical Practice. 2017. Available online: www.britsoc.co.uk/ media/24310/bsa_statement_of_ethical_practice.pdf (accessed on 16 March 2019).

62. Priya, K.R. The Research Relationship as a Facilitator of Remoralization and Self-Growth: Postearthquake Suffering and Healing. Qual. Health Res. 2014, 20, 479-495.

63. Starks, H.; Trinidad, S.B. Choose Your Method: A Comparison of Phenomenology, Discourse Analysis, and Grounded Theory. Qual. Health Res. 2007, 17, 1372-1380. [CrossRef] [PubMed]

64. Denzin, N.K.; Lecompte, M.D.; Millroy, W.L.; Preissle, J. The Handbook of Qualitative Research in Education. Contemp. Sociol. A J. Rev. 1993, 22, 290. [CrossRef]

65. Radford, L.; Corral, S.; Bradley, C.; Fisher, H.L. The prevalence and impact of child maltreatment and other types of victimization in the UK: Findings from a population survey of caregivers, children and young people and young adults. Child Abus. Negl. 2013, 37, 801-813. [CrossRef]

66. Finkelhor, D.; Ormrod, R.; Turner, H.; Holt, M. Pathways to Poly-Victimization. Child Maltreat. 2009, 14, 316-329. [CrossRef]

67. Felitti, V.J.; Anda, R.F.; Nordenberg, D.; Williamson, D.F.; Spitz, A.M.; Edwards, V.; Koss, M.P.; Marks, J.S. Relationship of Childhood Abuse and Household Dysfunction to Many of the Leading Causes of Death in Adults. Am. J. Prev. Med. 1998, 14, 245-258. [CrossRef]

68. Graham-Kevan, N.; Brooks, M.; Willan, V.; Lowe, M.; Robinson, P.; Khan, R.; Stokes, R.; Irving, M.; Karwacka, M.; Bryce, J. Repeat Victimisation, Retraumatisation and Victim Vulnerability. Open Criminol. J. 2015, 8, 36-48. [CrossRef]

69. Bloom, S.; Farragher, B. Destroying Sanctuary: The Crisis in Human Service Delivery Systems; Oxford University Pres: New York, NY, USA, 2010.

70. Pilowsky, D.J.; Keyes, K.M.; Hasin, D.S. Adverse Childhood Events and Lifetime Alcohol Dependence. Am. J. Public Health 2009, 99, 258-263. [CrossRef]

71. Edwards, R.; Gillies, V.; Lee, E.; Macvarish, J.; White, S.; Wastell, D. The Problem with ACEs'. Edwards et al.'s submission to the House of Commons Science and Technology Select Committee Inquiry into the evidence-base for early years intervention (EY10039). 12 December 2017. Available online: https://blogs.kent.ac.uk/parentingculturestudies/files/2018/01/The-Problem-with-ACEsEY10039-Edwards-et-al.-2017-1.pdf (accessed on 25 July 2020).

72. Metzler, M.; Merrick, M.T.; Klevens, J.; Ports, K.A.; Ford, D.C. Adverse childhood experiences and life opportunities: Shifting the narrative. Child. Youth Serv. Rev. 2017, 72, 141-149. [CrossRef] 
73. Taggart, D.; Mason, C.; Webb, S. Reconceptualising Non-Engagement in Child Protection; Frontline Briefing; Research in Practice: Dartington, UK, 2019.

74. Philip, G.; Bedston, S.; Hu, Y.; Youansamouth, L.; Clifton, J.; Broadhurst, K.; Brandon, M. 'Up Against It': Fathers and Recurrent Care Proceedings Final Report; Nuffield Foundation: London, UK, 2020.

Publisher's Note: MDPI stays neutral with regard to jurisdictional claims in published maps and institutional affiliations.

(C) 2020 by the authors. Licensee MDPI, Basel, Switzerland. This article is an open access article distributed under the terms and conditions of the Creative Commons Attribution (CC BY) license (http://creativecommons.org/licenses/by/4.0/). 